\title{
Improved health outcomes in patients with COPD during 1 yr's treatment with tiotropium
}

\author{
W. Vincken*, J.A. van Noord" ${ }^{\#}$, A.P.M. Greefhorst ${ }^{\Uparrow}$, Th.A. Bantje ${ }^{+}$, S. Kesten ${ }^{\S}$, L. Korducki ${ }^{\S}$, \\ P.J.G. Cornelissen ${ }^{f}$, on behalf of the Dutch/Belgian Tiotropium Study Group
}

Improved health outcomes in patients with COPD during $1 \mathrm{yr}^{\prime}$ s treatment with tiotropium. W. Vincken, J.A.van Noord, A.P.M. Greefhorst, Th.A. Bantje, S. Kesten, L. Korducki, P.J.G. Cornelissen, on behalf of the Dutch/Belgian Tiotropium Study Group. (C) ERS Journals Ltd 2002.

ABSTRACT: Tiotropium, a novel once-daily inhaled anticholinergic, has been shown to improve lung function over a 24-h period. In order to extend these findings, health-outcomes were evaluated over $1 \mathrm{yr}$ in chronic obstructive pulmonary disease (COPD) patients.

Spirometric results, peak expiratory flow rate (PEFR), salbutamol use and effects on dyspnoea, health-related quality of life and COPD exacerbations were assessed in two identical 1-yr randomized double-blind double-dummy studies of tiotropium $18 \mu \mathrm{g}$ once daily $(\mathrm{n}=356)$ compared with ipratropium $40 \mu \mathrm{g}$ q.i.d. $(\mathrm{n}=179)$.

Screening forced expiratory volume in one second (FEV1) were $1.25 \pm 0.43 \mathrm{~L}$ $(41.9 \pm 12.7 \%$ of the predicted value) (tiotropium) and $1.18 \pm 0.37 \mathrm{~L}(39.4 \pm 10.7 \%$ pred) (ipratropium). Trough FEV1 at 1 yr improved by $0.12 \pm 0.01 \mathrm{~L}$ with tiotropium and declined by $0.03 \pm 0.02 \mathrm{~L}$ with ipratropium $(p<0.001)$. Significant improvement in PEFR, salbutamol use, Transition Dyspnea Index focal score, and the St George's Respiratory Questionnaire total and impact scores were seen with tiotropium $(\mathbf{p}<\mathbf{0 . 0 1})$. Tiotropium reduced the number of exacerbations (by $24 \%, p<0.01$ ), and increased time to first exacerbation $(p<0.01)$ and time to first hospitalization for a COPD exacerbation $(p<0.05)$ compared with ipratropium. Apart from an increased incidence of dry mouth in the tiotropium group, adverse events were similar between treatments.

Tiotropium was effective in improving dyspnoea, exacerbations, health-related quality of life and lung function in patients with chronic obstructive pulmonary disease, and exceeds the benefits seen with ipratropium. The data support the use of tiotropium once-daily as first-line maintenance treatment in patients with chronic obstructive pulmonary disease.

Eur Respir J 2002; 19: 209-216.
*Respiratory Division, Academic Hospital University of Brussels (AZ VUB), Brussels, Belgium. ${ }^{\#}$ Dept of Respiratory Diseases, Atrium Medisch Centrum, Heerlen, the Netherlands. "Dept of Respiratory Diseases, St Streekziekenhuis Midden Twente, Hengelo, the Netherlands. ${ }^{+}$Dept of Respiratory Diseases, Ignatius and Barouie Hospitals, Breda, the Netherlands. ${ }^{8}$ Boehringer Ingelheim, Ridgefield, CT, USA ${ }^{f}$ Boehringer Ingelheim, Alkmaar, the Netherlands.

Correspondence: W. Vincken, Respiratory Division, AZ VUB (Academic Hospital University of Brussels), 101 Laarbeeklaan, 1090 Brussels, Belgium. Fax: 3224776019

E-mail: Walter.vincken@az.vub.ac.be

Keywords: Chronic obstructive pulmonary disease, dyspnoea, exacerbations, ipratropium, quality of life, tiotropium

Received: June 72001

Accepted after revision November 7 2001
Inhaled anticholinergics such as ipratropium have been recommended as first-line maintenance bronchodilator medication for chronic obstructive pulmonary disease (COPD) patients with regular symptoms $[1,2]$. Anticholinergic therapy is beneficial due to the increased cholinergic airway tone in COPD mediated through the vagus nerve [3].

The 6-h duration of action of ipratropium led to the search for and clinical development of tiotropium, a novel once-daily inhaled anticholinergic bronchodilator. The sustained bronchodilation caused by tiotropium is explained by its prolonged $\mathrm{M}_{3}$ muscarinic receptor antagonism [4, 5]. VAN NoORD et al. [6] recently published a study of 288 patients with COPD, documenting significant improvements in spirometric values over 3 months in patients receiving tiotropium $18 \mu \mathrm{g}$ once daily compared with ipratropium $40 \mu \mathrm{g}$ q.i.d. These patients continued into a 1-yr randomized double-blind trial. The present report describes the combined results of this study and a second large multicentre 1-yr trial comparing the effect of tiotropium $18 \mu \mathrm{g}$ once daily with that of ipratropium $40 \mu \mathrm{g}$ q.i.d. on lung function, dyspnoea, exacerbation rate and health-related quality of life (HRQOL) in patients with COPD.

\section{Methods}

\section{Study design}

The two 1-yr studies incorporated a randomized double-blind double-dummy parallel group design. Randomization to tiotropium $18 \mu \mathrm{g}$ once daily in the morning or ipratropium $40 \mu \mathrm{g}$ q.i.d. occurred on a 2:1 ratio, such that twice as many patients were exposed to tiotropium. Tiotropium was supplied as a dry powder capsule and inhaled through

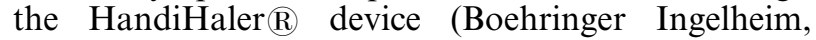
Ingelheim am Rhein, Germany). Ipratropium was administered using a metered-dose inhaler (MDI). Patients were permitted salbutamol MDIs (100 $\mu \mathrm{g}$ per actuation) as needed for acute symptom relief. Other $\beta$-agonists (long and short acting) and inhaled anticholinergic medications (other than study drugs) 
were not permitted. Concomitant use of theophyllines, inhaled steroids and oral steroids (at a dose of $\leqslant 10 \mathrm{mg} \cdot \mathrm{day}^{-1}$ prednisolone or equivalent) was allowed if the dosage was stable for $\geqslant 6$ weeks before screening.

The studies were conducted at 29 sites in the Netherlands and Belgium. The protocol was approved by independent ethics committees, and informed consent was obtained from all patients.

\section{Patients}

Patients were required to have a clinical diagnosis of COPD, a forced expiratory volume in one second (FEV1) of $\leqslant 65 \%$ of the predicted normal value [7] and $\leqslant 70 \%$ of forced vital capacity (FVC). Patients were also required to be $\geqslant 40$ yrs of age and have a smoking history of $\geqslant 10$ pack-yrs. Patients with a history of asthma, allergic rhinitis or atopy or an elevated total blood eosinophil count were excluded, as were patients requiring regular supplemental oxygen and those with a recent upper respiratory tract infection or a significant disease other than COPD.

\section{Study protocol}

Patients were randomized following screening and a 2-week baseline period. Spirometry was conducted in the outpatient clinic at screening and on day 1 (randomization) as well as after 1, 7, 13, 26, 39 and 52 weeks of therapy. Testing was performed $1 \mathrm{~h}$ before drug administration, immediately before drug administration, and at 30,60, 120 and $180 \mathrm{~min}$ after dosing (and at 240, 300 and $360 \mathrm{~min}$ on day 1 and at 1, 7 and 13 weeks). The highest FEV1 and FVC from three technically adequate measurements were retained. Peak expiratory flow rates (PEFRs) were self-measured by patients twice daily (upon arising and at bedtime) using a Mini-Wright Peak Flow Meter (Clement Clarke International, Harlow, UK). Patients were requested to record the best of three efforts. Patients also recorded the number of puffs of "as needed" salbutamol used.

Dyspnoea was evaluated using the Baseline Dyspnea Index (BDI) and the Transition Dyspnea Index (TDI) [8]. HRQOL was determined using the St George's Respiratory Questionnaire (SGRQ) [9] and the Medical Outcomes Study 36-Item Short-Form Health Survey (SF-36) [10].

Safety assessments included a complete blood count, biochemistry, urinalysis and electrocardiogram on entry and upon completion of the study. An exacerbation, identified through monitoring of adverse events, was defined as a complex of respiratory symptoms (i.e. new onset or worsening of more than one symptom such as cough, sputum, dyspnoea or wheeze) lasting $\geqslant 3$ days.

\section{Analysis}

Analysis of covariance with baseline as covariate was used, with terms for treatment and study centre.
Baseline FEV1 and FVC were set as the mean of the two measurements obtained on day 1 prior to the first dose of study medication. Trough FEV1 and FVC were calculated as the mean of the two predose measurements on subsequent clinic visits (i.e. 23-24 h after the preceding tiotropium dose or $\sim 8-9 \mathrm{~h}$ after the preceding ipratropium dose). The trough FEV1 response was defined as trough FEV1 minus baseline value. For PEFR and salbutamol use, the mean of observations obtained during the week before the treatment period were used as baseline data. For TDI focal score, a difference of $\geqslant 1$ unit was considered clinically meaningful. For the SGRQ impact and total scores, a difference of $\geqslant 4$ units was considered clinically meaningful. The proportions of patients with at least one COPD exacerbation or hospitalization due to an exacerbation over the 1-yr study period were compared using logistic regression adjusted for extent of exposure. For comparison of the number of COPD exacerbations, exacerbation days, hospitalizations due to exacerbation and hospitalization days across treatment groups, the Wilcoxon-Mann-Whitney test was used. The two treatment groups were also compared in terms of time to first exacerbation and time to first hospitalization due to an exacerbation using the log-rank test. Means were adjusted for baseline in the presentation of serial data over time. Statistical significance was considered at $\mathrm{p}<0.05$.

The intention-to-treat (ITT) principle was used to include as many randomized patients as possible in the analyses. This consisted of all patients for whom baseline data and data after multiple administration of study medication were available. In keeping with the ITT principle, patients were not excluded from any analyses due to protocol violations. Since the number of these was small, there was little or no impact on the results. For patients who discontinued the study early due to worsening of COPD, missing efficacy data were estimated using the least favourable data observed prior to discontinuation. Missing data for patients who missed a visit not related to worsening of COPD were estimated using their last observed data. In order to include the same patients at each time point in the spirometry summaries, missing values were estimated using other values recorded for the patient on that test day. Linear interpolation between the two adjacent measurements was used to estimate middle missing spirometry measurements. For values at the ends of the profiles that were missing because rescue medication was taken, the minimum observed FEV1 on that test day was used as the estimate. Patients who could not complete all visits due to drug expiration were requested to discontinue the study drug at the 9-month visit but were considered complete patients. Homogeneity of effect was measured for the primary endpoint by including an analysis with treatment by centre interaction and examining the effects for the various centres.

A sample size of 60 patients per group was calculated as adequate to detect a difference of $0.13 \mathrm{~L}$ in trough FEV1 based on an SD of $0.215 \mathrm{~L}$. To ensure adequate safety exposure, a sample size of 
Table 1. - Patients randomized and reason for withdrawal from the tiotropium and ipratropium groups

\begin{tabular}{lcc}
\hline & $\begin{array}{c}\text { Tiotropium } \\
\mathrm{n}(\%)\end{array}$ & $\begin{array}{c}\text { Ipratropium } \\
\mathrm{n}(\%)\end{array}$ \\
\hline Randomized & $356(100)$ & $179(100)$ \\
Completed trial & $302(84.8)$ & $141(78.8)$ \\
Withdrawn due to adverse events & $36(10.1)$ & $23(12.8)$ \\
$\quad$ Worsening of COPD & $11(3.1)$ & $11(6.1)$ \\
$\quad$ Worsening of other & $2(0.6)$ & $4(2.2)$ \\
$\quad$ pre-existing disease & $23(6.5)$ & $8(4.5)$ \\
$\quad$ Other adverse event & $3(0.8)$ & $3(1.7)$ \\
Withdrawn due to & & \\
lack of efficacy & $15(4.2)$ & $12(6.7)$ \\
Withdrawn for other reasons & $3(0.8)$ & $3(1.7)$ \\
$\quad$ Noncompliant with protocol & $2(0.6)$ & $0(0.0)$ \\
Lost to follow-up & $5(1.4)$ & $4(2.2)$ \\
Consent withdrawn & $5(1.4)$ & $5(2.8)$ \\
$\quad$ Miscellaneous &
\end{tabular}

COPD: chronic obstructive pulmonary disease.

240 patients (160 tiotropium and 80 ipratropium) was selected for each trial.

\section{Results}

\section{Patient demographics}

A total of 535 patients were randomized, 356 receiving tiotropium and 179 receiving ipratropium. More patients in the tiotropium group completed the trials compared to the ipratropium group (84.8 versus $78.8 \%$ ), predominantly due to fewer adverse events, including COPD exacerbations (table 1); however, there was no significant difference in the proportion of patients who completed the trial $(p=0.08$, Fisher's exact test). Thirteen per cent of patients in each treatment group (tiotropium, $n=47$; ipratropium, $\mathrm{n}=24$ ) were discontinued due to drug expiration. Although resupply of the study drug was originally planned, it was deemed unnecessary as the target sample size had been attained due to the lower-thanexpected frequency of early withdrawals over the year. Demographic data and respiratory medication use at screening were comparable across treatment groups (table 2). The screening FEV1 was $1.25 \pm 0.43 \mathrm{~L}(41.9 \%$ pred) and $1.18 \pm 0.37 \mathrm{~L}(39.4 \%$ pred $)$ for the tiotropium and ipratropium groups respectively (mean \pm SD).

\section{Spirometry}

Patients showed a significant bronchodilator response within $30 \mathrm{~min}$ after the first dose of tiotropium (fig. 1). By the end of the first week (day 8), the mean trough FEV1 ( $24 \mathrm{~h}$ after treatment with tiotropium and prior to the morning ipratropium dose) was $140 \mathrm{~mL}$ above baseline for patients in the tiotropium group (a 12\% increase) compared with $20 \mathrm{~mL}$ for those in the ipratropium group. Tiotropium was superior to ipratropium $(\mathrm{p}<0.05)$ at all time points on all test days except for the first $2 \mathrm{~h}$ following the first dose and up to $1 \mathrm{~h}$ after the dose 1 week later.
Table 2.-Demographic data and previous respiratory medication use on screening for the tiotropium and ipratropium groups

\begin{tabular}{lcc}
\hline & Tiotropium & Ipratropium \\
\hline Subjects n & 356 & 179 \\
Age yrs & $63.6 \pm 8.2$ & $64.5 \pm 8.1$ \\
Sex male/female \% & $84 / 16$ & $86 / 14$ \\
Duration of COPD yrs & $11.4 \pm 9.9$ & $11.2 \pm 9.6$ \\
Smoking pack-yrs & $34.3 \pm 18.6$ & $33.2 \pm 16.7$ \\
FEV1 L & $1.25 \pm 0.43$ & $1.18 \pm 0.37$ \\
FEV1\% pred & $41.9 \pm 12.7$ & $39.4 \pm 10.7$ \\
FVC L & $2.76 \pm 0.82$ & $2.62 \pm 0.74$ \\
FEV1/FVC \% & $45.7 \pm 10.4$ & $45.5 \pm 10.0$ \\
Respiratory medication & & \\
use n (\%) & & \\
Any pulmonary medication & $346(97.2)$ & $172(96.1)$ \\
Anticholinergic & $218(61.2)$ & $106(59.2)$ \\
$\beta$-Adrenergics (inhaled) & $272(76.4)$ & $135(75.4)$ \\
$\beta$-Adrenergics (oral) & $18(5.1)$ & $8(4.5)$ \\
Steroid (inhaled) & $286(80.3)$ & $145(81.0)$ \\
Steroid (oral) & $31(8.7)$ & $19(10.6)$ \\
Theophylline & $58(16.3)$ & $27(15.1)$ \\
\hline
\end{tabular}

Data are presented as mean \pm SD or $\mathrm{n}(\%)$. COPD: chronic obstructive pulmonary disease; FEV1: forced expiratory volume in one second; FVC: forced vital capacity; \% pred: percentage of the predicted value.

At the end of $1 \mathrm{yr}$, trough FEV1 was $120 \mathrm{~mL}$ above the day 1 baseline for patients receiving tiotropium, and had declined by $30 \mathrm{~mL}$ for those receiving ipratropium (difference of $150 \mathrm{~mL}$ between groups, $\mathrm{p}<0.001$ at all time points) (fig. 2). Further, this trough FEV1 was $20 \mathrm{~mL}$ lower than the trough FEV1 on day 8 (after pharmacodynamic steady state) for the tiotropium group, whereas for ipratropium this difference was $50 \mathrm{~mL}$.

The FVC results paralleled the FEV1 results. By the end of the first week, the mean trough FVC response $(\sim 24 \mathrm{~h}$ after treatment with tiotropium and prior to the morning ipratropium dose) was $320 \mathrm{~mL}$ for patients in the tiotropium group and $80 \mathrm{~mL}$ for the ipratropium group. The difference between the

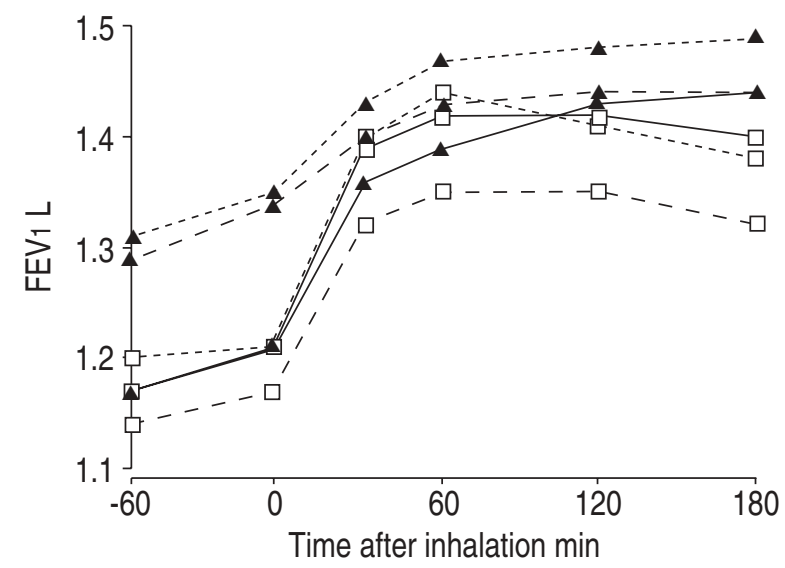

Fig. 1.- Mean forced expiratory volume in one second (FEV1) before and during the $3 \mathrm{~h}$ following inhalation of tiotropium $(\boldsymbol{\Delta})$ or ipratropium $(\square)$ at baseline (day 1, - $)$ and after 8 (- - - -) and $364(---)$ days. 


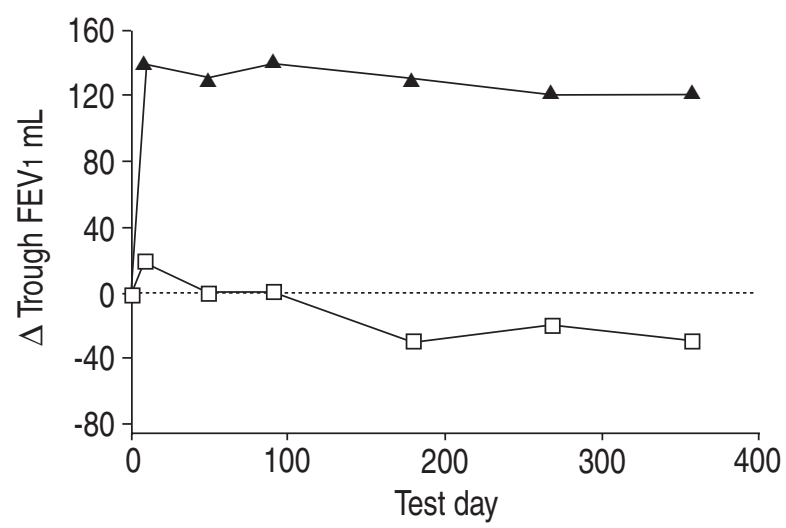

Fig. 2.- Mean change $(\Delta)$ in trough forced expiratory volume in one second $\left(F_{1}\right)$ following inhalation of tiotropium $(\boldsymbol{\Delta})$ or ipratropium $(\square)$ at baseline $(\cdot \cdots \cdots . . . .$.$) and throughout the 1-yr trials$ $(\mathrm{p}<0.001$ at all time points).

tiotropium and ipratropium response was significant $(\mathrm{p}<0.05)$ at trough and at all time points at $2 \mathrm{~h}$ and beyond on all test days. At the end of $1 \mathrm{yr}$, the trough FVC was $320 \mathrm{~mL}$ above the day 1 baseline for patients receiving tiotropium and $110 \mathrm{~mL}$ for those receiving ipratropium (mean difference of $210 \mathrm{~mL}$ between groups).

Spirometry results were consistent across centres.

\section{Peak expiratory flow rate}

Baseline morning and evening PEFRs for the tiotropium group $\left(253 \pm 4.1\right.$ and $262 \pm 4.1 \mathrm{~L} \cdot \mathrm{min}^{-1}$, respectively) were comparable to those for the ipratropium group $\left(244 \pm 5.9\right.$ and $254 \pm 6.0 \mathrm{~L} \cdot \mathrm{min}^{-1}$, respectively). Throughout the $1-y r$ treatment period, morning and evening PEFR improved significantly more in the tiotropium group than in the ipratropium group ( $p<0.01$ at all weekly intervals). The difference between the two groups ranged $10-18 \mathrm{~L} \cdot \mathrm{min}^{-1}$ in the morning and $9-18 \mathrm{~L} \cdot \mathrm{min}^{-1}$ in the evening.

\section{Dyspnoea}

The BDI focal scores (mean \pm SEM) for the tiotropium group $(7.13 \pm 0.14)$ and ipratropium group $(7.41 \pm 0.19)$ were comparable. Tiotropium significantly improved all three components of the TDI, as well as the focal score, on all test days compared to ipratropium $(\mathrm{p}<0.05)$. The differences in TDI focal score between the tiotropium and ipratropium groups at 9 and 12 months were $0.97 \pm 0.25$ and $0.90 \pm 0.26$, respectively (fig. 3a, table 3 ). The proportion of patients who achieved a clinically meaningful difference in TDI focal score (improvement of $\geqslant 1$ unit) at $1 \mathrm{yr}$ was significantly greater in the tiotropium group (31\%) than in the ipratropium group $(18 \%, \mathrm{p}=0.004)$ (fig. 3b). Based on the results of the study, the number needed to treat (NNT) to obtain at least a 1-unit improvement in the TDI focal score over a population that would otherwise receive regular ipratropium would be eight.
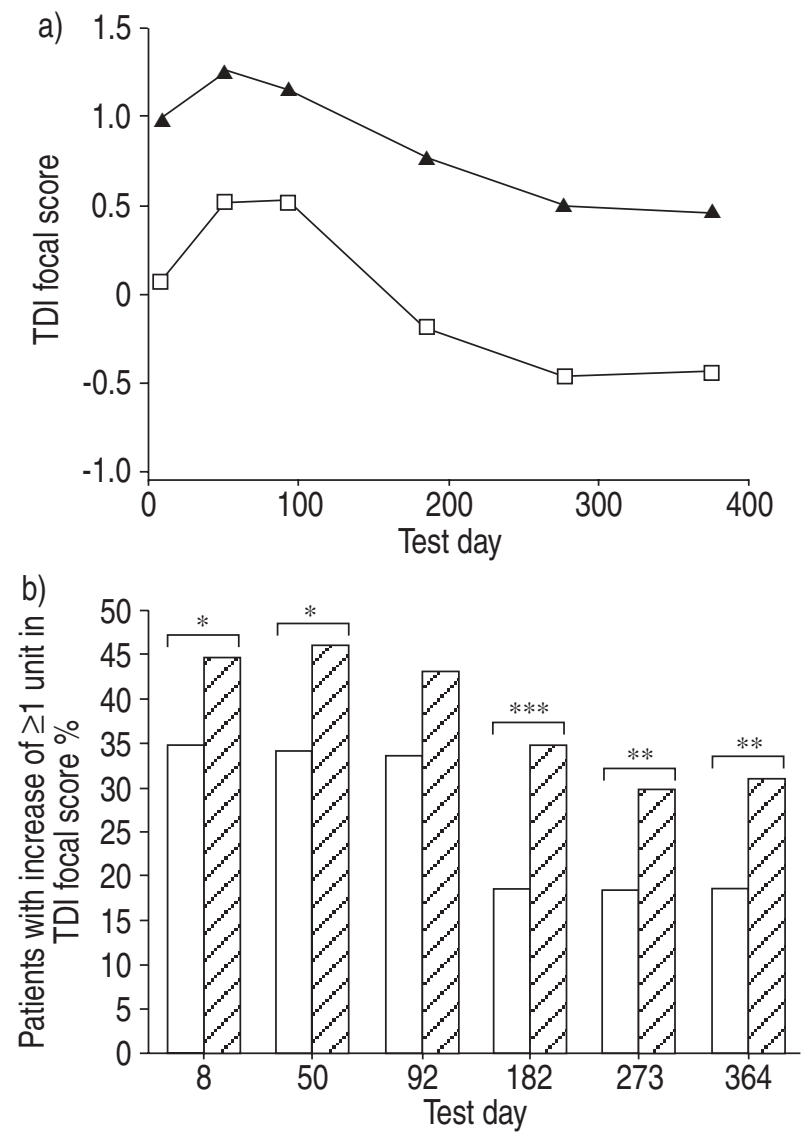

Fig. 3.-a) Mean Transition Dyspnoea Index (TDI) focal score over 1 yr for the tiotropium $(\boldsymbol{\Delta})$ and ipratropium $(\square)$ groups. b) Proportion of patients with an increase (improvement) TDI focal score of $\geqslant 1$ unit for the tiotropium $(\square)$ and ipratropium $(\square)$ groups during the 1-yr study. *: $\mathrm{p}<0.05$; **: $\mathrm{p}<0.01 ; * * *: \mathrm{p}<0.001$.

\section{Health-related quality of life}

At baseline, the SGRQ total scores (mean \pm SEM) for tiotropium and ipratropium were similar $(45.4 \pm 0.92$ and 43.2 \pm 1.36 , respectively). During the $1-y r$ treatment period, the SGRQ total score decreased (improved) in both groups, but gradually returned towards baseline in the ipratropium group (fig. 4a). Improvements were maintained over the year in the tiotropium group, and were superior to ipratropium (difference of $3.30 \pm 1.13$ on day $364, \mathrm{p}<0.05$ ) (table 3 ). At $1 \mathrm{yr}$, the mean change from baseline in SGRQ total score was -3.74 for tiotropium and -0.44 for ipratropium. From day 92 to the end of the study, the improvement in the impacts score was significantly greater with tiotropium than with ipratropium $(\mathrm{p}=0.004)$. The difference between the two groups in the impacts score was $4.28 \pm 1.32$ on day 364 ( $\mathrm{p}=0.001)$. For both the symptoms and activities domains, similar improvements were seen in both groups (table 3).

More patients in the tiotropium group than in the ipratropium group achieved the clinically meaningful improvement of 4 units in the SGRQ total score after 9 and 12 months (52 versus 35\% respectively, at $1 \mathrm{yr}$, $\mathrm{p}=0.001$ ) (fig. 4b). The NNT to obtain at least a 4-unit 
Table 3. - St George's Respiratory Questionnaire (SGRQ), Medical Outcomes Study 36-Item Short-Form Health Survey (SF-36) and Transition Dyspnea Index (TDI) focal score results at the end of the trial in the ipratropium and tiotropium groups

\begin{tabular}{|c|c|c|c|c|c|}
\hline & Ipratropium & Tiotropium & Difference & $95 \% \mathrm{CI}$ & p-value \\
\hline \multicolumn{6}{|l|}{ SGRQ } \\
\hline Symptoms & $50.47 \pm 1.49$ & $47.32 \pm 1.07$ & $-3.15 \pm 1.73$ & $-6.55-0.26$ & 0.070 \\
\hline Activities & $56.21 \pm 1.17$ & $55.07 \pm 0.84$ & $-1.14 \pm 1.36$ & $-3.82-1.53$ & 0.401 \\
\hline Impacts & $35.23 \pm 1.14$ & $30.95 \pm 0.81$ & $-4.28 \pm 1.32$ & $-6.87-1.68$ & 0.001 \\
\hline Total & $44.20 \pm 0.97$ & $40.90 \pm 0.69$ & $-3.30 \pm 1.13$ & $-5.51-1.09$ & 0.004 \\
\hline \multicolumn{6}{|l|}{ SF-36 } \\
\hline Physical function & $52.20 \pm 1.40$ & $54.32 \pm 1.00$ & $2.11 \pm 1.62$ & $-1.08-5.30$ & 0.194 \\
\hline Role physical & $49.46 \pm 2.88$ & $56.62 \pm 2.05$ & $7.16 \pm 3.34$ & $0.59-13.73$ & 0.033 \\
\hline Bodily pain & $76.57 \pm 1.69$ & $79.47 \pm 1.21$ & $2.89 \pm 1.96$ & $-0.96-6.75$ & 0.141 \\
\hline General physical health & $47.01 \pm 1.29$ & $49.89 \pm 0.92$ & $2.88 \pm 1.50$ & $-0.06-5.82$ & 0.055 \\
\hline Physical health summary & $38.49 \pm 0.59$ & $40.16 \pm 0.42$ & $1.68 \pm 0.69$ & $0.33-3.02$ & 0.015 \\
\hline Vitality & $57.56 \pm 1.25$ & $60.35 \pm 0.89$ & $2.79 \pm 1.45$ & $-0.06-5.64$ & 0.055 \\
\hline Social function & $74.68 \pm 1.75$ & $76.07 \pm 1.25$ & $1.39 \pm 2.02$ & $-2.59-5.37$ & 0.493 \\
\hline Role emotional & $63.86 \pm 2.95$ & $70.29 \pm 2.10$ & $6.44 \pm 3.42$ & $-0.28-13.15$ & 0.060 \\
\hline General mental health & $75.40 \pm 1.17$ & $76.12 \pm 0.84$ & $0.71 \pm 1.36$ & $-1.96-3.39$ & 0.600 \\
\hline Mental health summary & $50.90 \pm 0.70$ & $51.82 \pm 0.50$ & $0.93 \pm 0.82$ & $-0.68-2.53$ & 0.258 \\
\hline \multicolumn{6}{|l|}{ TDI } \\
\hline Focal score & $-0.44 \pm 0.23$ & $0.46 \pm 0.16$ & $0.90 \pm 0.26$ & $0.37-1.41$ & 0.001 \\
\hline
\end{tabular}

Data are presented as mean \pm SEM or range. CI: confidence interval.
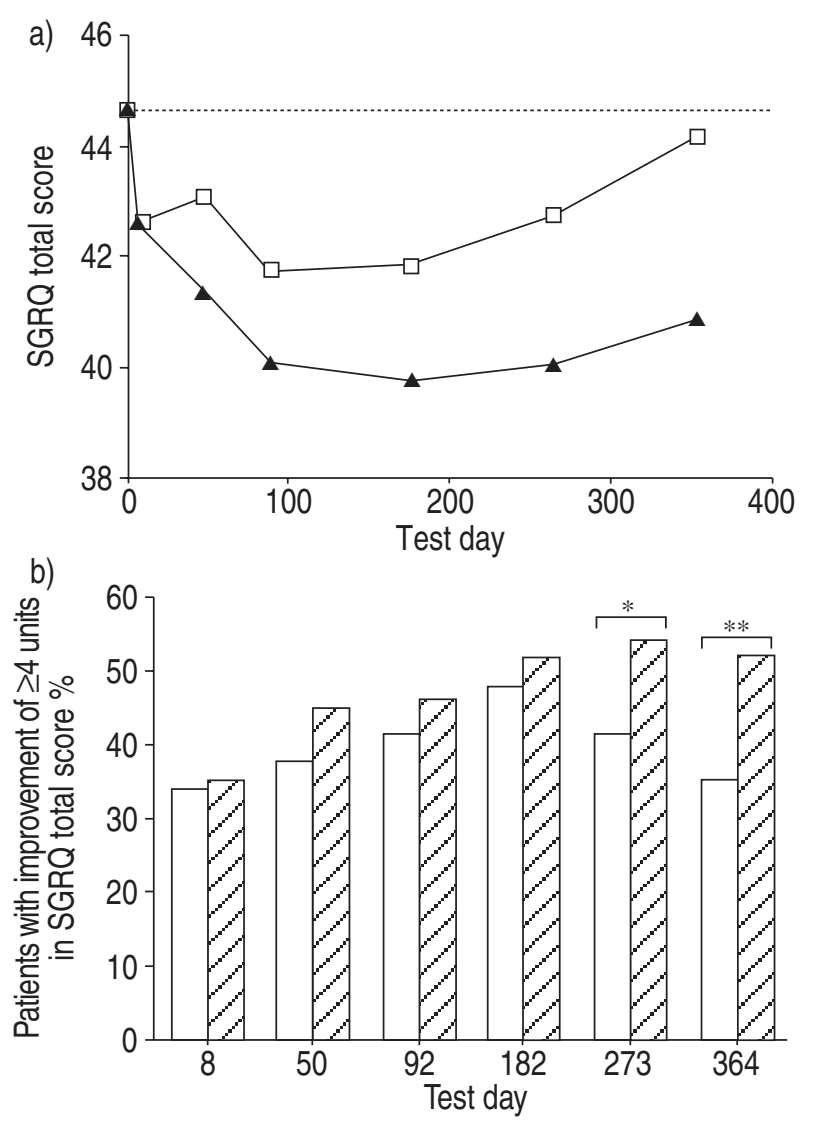

Fig. 4. - a) Mean St George's Respiratory Questionnaire (SGRQ) total score over $1 \mathrm{yr}$ for the tiotropium $(\mathbf{\Lambda})$ and ipratropium $(\square)$ groups (……: baseline). b) Proportion of patients with an improvement in SGRQ total score of $\geqslant 4$ units for the tiotropium $(\square)$ and ipratropium $(\square)$ groups during the 1 -yr study. $*$ : p $<0.05$; $* *: \mathrm{p}<0.001$. improvement in SGRQ total score over a population that would otherwise receive regular ipratropium would be six.

SF-36 baseline data were comparable across the two treatment groups. Tiotropium was more effective than ipratropium in all physical domains (higher scores); however, the differences between the treatment groups were only significant in physical health summary on the last 2 test days (days 273 and 364). In the mental health domains, the differences in scores between the treatment groups were less consistent and were generally not significant (table 3 ).

\section{Exacerbations of chronic obstructive pulmonary disease}

The proportion of patients experiencing one or more exacerbations during the 1-yr treatment period was significantly lower in the tiotropium group than in the ipratropium group (35 versus $46 \%$, respectively, $\mathrm{p}=0.014)$. The number of exacerbations $\cdot$ patient ${ }^{-1} \cdot \mathrm{yr}^{-1}$ was $24 \%$ lower in the tiotropium group $(0.73$ versus $0.96, \mathrm{p}=0.006)$. In addition, the number of exacerbation days $\cdot$ patient $^{-1} \cdot \mathrm{yr}^{-1}$ was $39 \%$ lower in the tiotropium group (10.8 versus $17.7, \mathrm{p}=0.002)$. The time to first exacerbation was significantly longer in patients receiving tiotropium $(\mathrm{p}=0.008)$ (fig. 5a).

Similar findings were observed for hospitalizations due to COPD exacerbations during the 1-yr treatment period. The proportion of patients hospitalized for a COPD exacerbation were 7.3 and $11.7 \%$ in the tiotropium and ipratropium groups, respectively $(\mathrm{p}=0.11)$. The number of hospitalizations $\cdot$ patient $\mathrm{t}^{-1} \cdot \mathrm{yr}^{-1}$ for a COPD exacerbation was 38\% lower in the tiotropium group $(0.10$ versus $0.16, p=0.08)$, and the number of hospitalization days $\cdot$ patient $^{-1} \cdot \mathrm{yr}^{-1}$ was $33 \%$ lower in patients receiving tiotropium (1.42 versus $2.13, \mathrm{p}=0.09)$. Furthermore, the time to first 

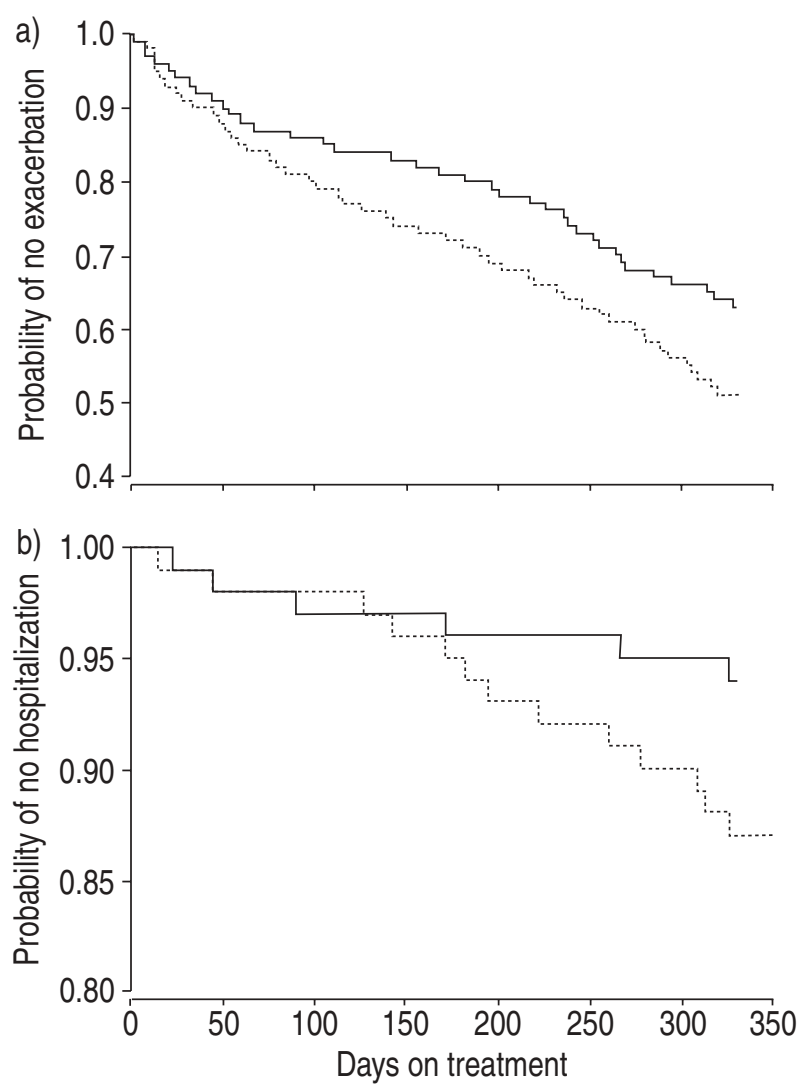

Fig. 5.-Kaplan-Meier estimates of the probability of: a) no exacerbation ( $\mathrm{p}=0.008$ for time to first exacerbation); and $b)$ no hospitalization ( $\mathrm{p}=0.048$ for time to first hospitalization) due to a chronic obstructive pulmonary disease exacerbation for the tiotropium $(-)$ and ipratropium $(\cdots \cdots \cdots \cdots)$ groups during the $1-\mathrm{yr}$ study.

hospitalization due to a COPD exacerbation was significantly longer in the tiotropium group $(\mathrm{p}=0.048)$ (fig. 5b).

\section{Use of as needed (rescue) salbutamol}

On average, patients receiving tiotropium selfadministered approximately four fewer inhalations of salbutamol-week ${ }^{-1}$ compared to patients receiving ipratropium $(\mathrm{p}<0.05$ for 40 of the 52 weeks $)$.

\section{Safety}

The proportions of patients experiencing adverse events leading to discontinuation were 10.1 and $12.8 \%$ in the tiotropium and ipratropium groups, respectively. These differences, although not significant $(\mathrm{p}=0.089)$, were predominantly the result of fewer respiratory events. There were no differences in the proportion of patients who died during the trial (tiotropium, 2.5\% (n=9); ipratropium, 1.7\% (n=3)). The only adverse event consistently reported as possibly related to tiotropium was dry mouth, which was noted more frequently with tiotropium $(12.1 \%)$ than with ipratropium $(6.1 \%)(p=0.03$, Fisher's exact test). Dry mouth was generally reported as mild, resolved during treatment in the majority of patients and did not lead to discontinuation in any patient receiving tiotropium. No laboratory or electrocardiographic abnormalities were observed that could be attributed to tiotropium.

\section{Discussion}

The present trials provide long-term information on the bronchodilatory benefits of tiotropium, a novel once-daily inhaled anticholinergic bronchodilator, compared to ipratropium, a medication widely used in the treatment of COPD. The results indicate that tiotropium provides sustained improvements in lung function, dyspnoea, exacerbations and HRQOL over $24 \mathrm{~h}$ throughout $1 \mathrm{yr}$ of treatment. The results support a previous single-dose study in patients with COPD, which showed that once-daily dosing with tiotropium results in significant spirometric changes $24 \mathrm{~h}$ later [11]. A placebo-controlled 4-week doseranging study supported the $24-\mathrm{h}$ effects on spirometry with once-daily tiotropium [12].

Treatment with ipratropium leads to significant bronchodilation, with recent data suggesting other tangible benefits such as improvement in dyspnoea and hyperinflation and decreased exacerbations of COPD [13-17]. However, although effective, the recommended four times daily dosing leads to diminished compliance [18] and possibly suboptimal benefits from bronchodilator therapy. Tiotropium has the advantage of once-daily dosing, enhancing convenience and eliminating the need to carry maintenance medication whilst away from home. More importantly, in the present study, the prolonged bronchodilation achieved with tiotropium provides superior benefits in pulmonary function (FEV1 and FVC), dyspnoea, exacerbations and HRQOL compared to ipratropium.

In addition to the $24-\mathrm{h}$ bronchodilation, it was interesting to note that the loss of lung function (based on predose morning FEV1) from day 8 (pharmacodynamic steady state for tiotropium) to $1 \mathrm{yr}$ was only $20 \mathrm{~mL}$ for tiotropium compared with a loss of $50 \mathrm{~mL}$ for ipratropium, suggesting a slowing of the rate of decline in lung function over time. Definitive conclusions would require a longer study period.

Dyspnoea is the most frequent complaint of patients with COPD requiring medical intervention and is the most prominent symptom limiting the activity of daily living. The TDI is a validated questionnaire that quantifies and distinguishes changes in breathlessness over time in COPD patients [8]. In a 12-week study of 411 patients with symptomatic COPD (mean FEV1 $\sim 40 \%$ pred), ipratropium improved TDI scores relative to placebo at the end of the trial, whereas salmeterol was of no significant benefit [17]. The present study demonstrates that tiotropium was superior to ipratropium in improving dyspnoea at all time points over $1 \mathrm{yr}$, as assessed by the difference in mean TDI scores, and by the proportion of subjects who demonstrated a clinically meaningful improvement $(\geqslant 1$ unit change in focal score). Reduction in dyspnoea due to bronchodilators 
such as tiotropium is probably secondary to improvements in both airflow limitation and hyperinflation [19].

Assessment of HRQOL can be accomplished using both generic and disease-specific quality-of-life questionnaires. Disease-specific questionnaires for COPD have shown a weak correlation with lung function, but provide additional useful information over and above standard spirometric indices [9]. There are conflicting reports as to the effectiveness of salmeterol in improving HRQOL. JoNES and BosH [20] noted an improvement in SGRQ scores of $>4$ units over placebo with salmeterol $50 \mu \mathrm{g}$ b.i.d. but not $100 \mu \mathrm{g}$ b.i.d. Rutten-van Molken et al. [21], in a study of health status questionnaires, did not notice any differences between salmeterol and placebo, although the full data have yet to be published. The present study suggests that questionnaire-based assessments of HRQOL can distinguish effects between bronchodilators. The benefits seen with tiotropium compared to ipratropium were noted with both the generic (SF-36) and disease-specific (SGRQ) questionnaires. Based on the present study, tiotropium appears to improve and maintain HRQOL, whereas regular ipratropium is not associated with long-term improvements.

As COPD progresses, the increased frequency and severity of exacerbations become notable [22]. Hospitalizations due to exacerbations of COPD, particularly when admission to an intensive care unit is required, are predictive of an earlier mortality from COPD [23, 24]. In addition, increased exacerbation frequency has been associated with worsening quality of life [25].

A medical intervention that prevents exacerbations rather than treating established events would be desirable. The Inhaled Steroids in Obstructive Lung Disease (ISOLDE) study suggested that inhaled steroids might be effective in reducing exacerbations [26]. However, limited data exist demonstrating the effectiveness of bronchodilators in preventing exacerbations [16]. In the 12-week trial comparing salmeterol to ipratropium and placebo reported by Rennard et al. [27], there were no differences in the percentages of patients who experienced one or more COPD exacerbations. More patients experienced exacerbations in the first week in the placebo group compared to either the salmeterol or ipratropium groups. In the present study, tiotropium, compared to ipratropium, not only prolonged the time to first exacerbation but also reduced the frequency of exacerbations and the number of exacerbation days. Further, the first hospitalization due to exacerbation was delayed and, although not statistically significant, there was also a trend towards reduced hospitalizations and days in hospital due to a COPD exacerbation.

The association of treatment with the long-acting bronchodilator tiotropium and reduction in exacerbations raises the interesting question of mechanistic explanations. One possibility is that the severity of symptoms, induced by triggers such as viral infections, is reduced through sustained bronchodilation, such that the patient does not require medical attention. A shift in severity of symptoms may translate into an outpatient visit and therapy at home rather than an urgent visit to an accident and emergency department with hospitalization. Given the enormous impact of exacerbations on the patient, and on the healthcare system, tiotropium has the potential to affect broader issues beyond symptomatic improvement.

New pharmacological entities should undergo comparative clinical trials against the best available options in studies of reasonable duration in order to appropriately position medications in treatment algorithms. In this regard, tiotropium has been compared with the presently recommended first-line therapy, ipratropium, over $1 \mathrm{yr}$ and shows improved benefits in addition to a considerably more convenient dosing regimen.

Decisions in the management of chronic obstructive pulmonary disease require consideration of multiple outcome measures. Although spirometry remains foundational in diagnosis and demonstration of efficacy, symptoms, quality of life and prevention of exacerbations are of more concern to the patient and their family. In the present study, tiotropium showed consistently greater efficacy across all of the aforementioned outcome measures compared to ipratropium. Given the comparative data, once-daily administration of tiotropium should be considered as first-line maintenance treatment in patients with chronic obstructive pulmonary disease.

\footnotetext{
Members of the DutchlBelgian Tiotropium Study Group: Th.A. Bantje, Breda; J.M.M. van de Bosch, Nieuwegein; M.C.M. Bunnik, Boxmeer; J.P.H.M. Creemers, Hengelo; W.H. Dalinghaus, Amersfoort; M.E. Eland, Dordrecht; W.B.M. Evers, Sneek; S.J.M. Gans, Harderwijk; H.Ch. Gooszen, Eindhoven; A.P.M. Greefhorst, Hengelo; A.J. van Harreveld, Apeldoorn; J.H.L.M. van Kasteren, Geldrop; A.F. Kuipers, Zwolle; J.A. van Noord, Heerlen; G.D. Nossent, Groningen; B.J.M. Pannekoek, Delft; H.R. Pasma, Leeuwarden; A. Peters, Blaricum; W.R. Pieters, Helmond; P.E. Postmus, Amsterdam; A.J.M. Schreurs, Amsterdam; H.E.J. Sinninghe Damsté, Almelo; A.P. Sips, Utrecht; P.I. van Spiegel, Amsterdam; J. Westbroek, Heerenveen, (the Netherlands); J.L. Aumann, Hasselt; E. Janssens, Lanaken; R. Pauwels, Ghent; M. Radermecker, Liège; H. Slabbynck, Antwerp; I. Stappaerts, Antwerp; J. Verhaert, Lanaken; P. Vermeire, Antwerp; W. Vincken, Brussels (Belgium).
}

\section{References}

1. Siafakas NM, Vermeire P, Pride NB, et al. Optimal assessment and management of chronic obstructive pulmonary disease (COPD). The European Respiratory Society Task Force. Eur Respir J 1995; 8: 1398 1420.

2. American Thoracic Society. Standards for the diagnosis and care of patients with chronic obstructive pulmonary disease (COPD). Am J Respir Crit Care Med 1995; 152: S77-S120.

3. Gross NJ, Skorodin MS. Role of the parasympathetic 
system in airway obstruction due to emphysema. $N$ Engl J Med 1984; 311: 421-425.

4. Barnes PJ, Belvisi MG, Mak JCW, Haddad E, $\mathrm{O}^{\prime}$ Connor B. Tiotropium bromide $(\mathrm{Ba} 679 \mathrm{Br})$, a novel long-acting muscarinic antagonist for the treatment of obstructive airways disease. Life Sci 1995; 56: 853-859.

5. Disse B, Speck GA, Rominger KL, Witek TJ, Hammer R. Tiotropium (Spiriva): mechanistical considerations and clinical profile in obstructive lung disease. Life Sci 1999; 64: 457-464.

6. van Noord JA, Bantje ThA, Eland ME, Korducki L, Cornelissen PJG. A randomised controlled comparison of tiotropium and ipratropium in the treatment of COPD. Thorax 2000; 55: 289-294.

7. Quanjer PH, Tammeling GJ, Cotes JE, Pedersen OF, Peslin R, Yernault J-C. Lung volumes and forced ventilatory flows. Report Working Party Standardization of Lung Function Tests, European Community for Steel and Coal. Eur Respir J 1993; 6: Suppl. 16. 5-40.

8. Mahler DA, Weinber DH, Wells CK, Feinstein AR. The measurement of dyspnea: contents, interobserver agreement, and physiologic correlates of two new clinical indexes. Chest 1984; 85: 751-758.

9. Jones PW, Quirk FH, Baveystock CM, Littlejohns P. A self-complete measure of health status for chronic airflow limitation. Am Rev Respir Dis 1992; 145: 13211327.

10. Ware JE, Sherbourne CD. The MOS 36-Item ShortForm Health Survey (SF-36). Med Care 1992; 30: 473483.

11. Maesen F, Smeets J, Sledsens T, Wald F, Cornelissen P. Tiotropium bromide, a new long-acting antimuscarinic bronchodilator: a pharmacodynamic study in patients with chronic obstructive pulmonary disease (COPD). Eur Respir J 1995; 8: 1506-1513.

12. Littner MR, Ilowite JS, Tashkin DP, et al. Longacting bronchodilation with once daily dosing of tiotropium (Spiriva ${ }^{\mathrm{TM}}$ ) in stable chronic obstructive pulmonary disease. Am J Respir Crit Care Med 2000; 161: 1136-1142.

13. Karpel JP. Bronchodilator responses to anticholinergic and $\beta$-adrenergic agents in acute and stable COPD. Chest 1991; 99: 871-876.

14. LeDoux EJ, Morris JF, Temple WP, Duncan C. Standard and double dose ipratropium bromide and combined ipratropium bromide and inhaled metaproterenol in COPD. Chest 1989; 95: 1013-1016.

15. O'Donnell DE, Lam M, Webb KA. Spirometric correlates of improvement in exercise performance after anticholinergic therapy in chronic obstructive pulmonary disease. Am J Respir Crit Care Med 1999; 160: 542-549.

16. Friedman M, Serby CW, Menjoge SS, Wilson JD,
Hilleman DE, Witek TJ Jr. Pharmacoeconomic evaluation of a combination of ipratropium plus albuterol compared with ipratropium alone and albuterol alone in COPD. Chest 1999; 115: 635-641.

17. Mahler DA, Donohue JF, Barbee RA, et al. Efficacy of salmeterol xinafoate in the treatment of COPD. Chest 1999; 115: 957-965.

18. Rand CS, Nides M, Cowles MK, Wise RA, Connett J. Long-term metered-dose inhaler adherence in a clinical trial. The Lung Health Study Research Group. Am J Respir Crit Care Med 1995; 152: 580588.

19. Belman MJ, Botnick WC, Shin JW. Inhaled bronchodilators reduce dynamic hyperinflation during exercise in patients with chronic obstructive pulmonary disease. Am J Respir Crit Care Med 1996; 153: 967-975.

20. Jones PW, Bosh TK. Quality of life changes in COPD patients treated with salmeterol. Am J Respir Crit Care Med 1997; 155: 1283-1289.

21. Rutten-van Molken M, Roos B, Van Noord JA. An empirical comparison of the St George's Respiratory Questionnaire (SGRQ) and the Chronic Respiratory Disease Questionnaire (CRQ) in a clinical trial setting. Thorax 1999; 54: 995-1003.

22. Greenberg SB, Allen M, Wilson J, Atmar RL. Respiratory viral infections in adults with and without chronic obstructive pulmonary disease. Am J Respir Crit Care Med 2000; 162: 167-173.

23. Keistinen T, Tuuponen T, Kivela SL. Survival experience of the population needing hospital treatment for asthma or COPD at age 50-54 years. Respir Med 1998; 92: 568-572.

24. Seneff MG, Wagner DP, Wagner RP, Zimmerman JE, Knaus WA. Hospital and 1-year survival of patients admitted to intensive care units with acute exacerbation of chronic obstructive pulmonary disease. JAMA 1995; 274: 1852-1857.

25. Seemungal TA, Donaldson GC, Paul EA, Bestall JC, Jeffries DJ, Wedzicha JA. Effect of exacerbation on quality of life in patients with chronic obstructive pulmonary disease. Am J Respir Crit Care Med 1998; 157: 1418-1422.

26. Burge PS, Calverley PM, Jones PW, Spencer S, Anderson JA, Maslen TK. Randomised, double blind, placebo controlled study of fluticasone propionate in patients with moderate to severe chronic obstructive pulmonary disease: the ISOLDE trial. BMJ 2000; 320: 1297-1303.

27. Rennard SI, Anderson W, ZuWallack R, et al. Use of a long-acting inhaled $\beta_{2}$-adrenergic agonist, salmeterol xinfoate, in patients with chronic obstructive pulmonary disease. Am J Respir Crit Care Med 2001; 163: 1087-1092. 